Indonesian Journal of EFL and Linguistics

Vol. 3 No. 1, 2018

eISSN: 2503-4197, pISSN: 2527-5070

www. indonesian-efl-journal.org

\title{
L2 Writing Proficiency and Mastery of Complex Sentence: A Study of Indonesian English Education Major University Students
}

\author{
Adaninggar Septi Subekti \\ English Education Department, Duta Wacana Christian University, Indonesia \\ e-mails: adaninggarseptisubekti@gmail.com, adaninggar@staff.ukdw.ac.id
}

\begin{abstract}
:
This study investigated the extent of learners' mastery of complex sentences in predicting L2 writing proficiency. This study used forty essays of ten students of English Education Department. It found that complex sentences became the most frequently written sentences in the analysed essays. The mean of their level of mastery was 57.58\%, suggesting that their mastery in general was quite low. Furthermore, learners' number of complex sentences did not have any significant relationship with L2 writing proficiency, $r(40)=-.08, p>.05$, but their level of mastery of complex sentences positively correlated with their writing proficiency, $r$ $(40)=.44, p<.01$, suggesting that number of complex sentences regardless of grammaticality did not significantly correlate with L2 writing proficiency and only grammatically correct complex sentences, seen through learners' mastery, had positive correlation with L2 writing proficiency. Furthermore, learners' mastery of complex sentences could predict $19 \%$ of their writing proficiency, $R^{2}=.19$. From the results, implications and limitations of the study as well as suggestions on future studies were stated.
\end{abstract}

Keywords: L2 writing proficiency, complex sentences, mastery

Indonesian Journal of EFL and Linguistics, Vol. 3(1), 2018 


\section{INTRODUCTION}

Second language (L2) learning typically involves various aspects, among which writing plays in a very important role. Learners typically need to learn four basic skills of the language, which are reading, listening, speaking, as well as writing, and three basic elements, which are vocabulary or lexicon, grammar, and pronunciation. Among Indonesian learners of English, writing, more specifically, is probably often considered relatively more difficult compared to the other language skills. In regard with this, Oshima and Hogue (2006) attributed learners' difficulties in writing to the various components learners need to master in order to write well. They include content, organization, language use, vocabulary or lexicon, as well as mechanics such as spelling and punctuations (Oshima \& Hogue, 2006).

Furthermore, Hartfield, Jacobs, Zinkgraft, Wormuth, and Hughey (1985) asserted that communicating ideas to readers becomes the primary purpose of writing and thus contents become the most important component of writing and the other components, such as language use, vocabulary, organization, and mechanics, should support this primary purpose. In other words, writing proficiency can be measured through how well learners convey their ideas or topics using accurate grammar, coherent organization, various and relevant dictions, as well as good mechanics (Hartfield et al., 1985).

In relation with that, grammar is often considered a frame through which learners can express ideas or meaning (Krashen \& Terrell, 1983; Radford, 1990) and as such grammar mastery is an important aspect contributing to writing performance. Bram (1995), however, asserted that writing grammatically accurate sentences in writing is not enough. Expressing ideas in complex sentences, he continued, will enhance the flow of thoughts much more smoothly compared to expressing ideas in series of simple sentences. That is because complex sentences allow learners to put emphasised ideas in independent clauses, and the less important idea in dependent clauses. This statement gives some kind of support to the importance of the mastery of complex sentences in enhancing writing performance compared to other grammatical aspects.

\subsection{Rationales}

Acknowledging the importance of complex sentence in writing, Cahyono, Mukminatien, and Amrina (2016) investigated the relationship between the number of complex sentences learners' write and their L2 writing proficiency with undergraduate students of English Department as the participants. They found that there was a significant correlation between the number of complex sentences and learners' L2 writing proficiency. As such, there was a tendency that the more complex sentences students wrote the higher their writing scores tended to be. They also found that complex sentences became the most frequently written sentences among all types of sentences. In line with that, Subekti (2017) found that $48.5 \%$ of all sentences English Education undergraduate student participants wrote in their essays were complex sentences. 
Despite the possible contributions of the previous studies on complex sentences in writing contexts among Indonesian students above, there are still some points that need to be further investigated. First, Cahyono et al.'s (2016) study investigated the relationship between L2 writing proficiency and the number of complex sentences, whether or not these sentences were grammatical. Some people may be left wondering whether or not the accuracy of these written complex sentences contributed to learners' L2 writing proficiency as measured with their scores. There was also a possibility that these complex sentences contained errors and still significantly had positive correlation with writing scores regardless. However, if the intention is to find the possible role of grammar in writing context, investigation of the relationship between learners' mastery of complex sentence seen from the percentage of correct complex sentences rather than merely the number of complex sentences per se should be more emphasised. In addition, this study can inform both teachers of Writing class and Structure class at any English Education Departments in Indonesia on possible pedagogical actions in accordance with the findings in the field of grammar especially complex sentences, writing, and the relationship between them.

\subsection{Research questions}

Based on the rationales mentioned above, this study seeks to answer the following research questions:

1. How is the relationship between their number of complex sentences and their L2 writing proficiency?

2. How is the English Education Department's students' mastery of complex sentences?

3. To what extent does their mastery of complex sentences predict their L2 writing proficiency?

\section{LITERATURE REVIEW}

\subsection{Debates on the Position of Grammar Teaching in L2 Learning}

Before the elaboration on complex sentences, the bigger umbrella under which complex sentences are located in L2 learning components, grammar, should be put forward first. Despite the importance of grammar, many Indonesian learners of English probably consider grammar a boring and difficult aspect of learning. Despite the importance of grammar mastery, Ariyanti ( 2016) stated that grammatical aspects still become an obstacle for Indonesian students. They may associate learning grammar with memorising rules their teachers write on boards and producing language in accuracy in accordance with the rules in, very often, isolated written forms like cloze-tests and fill-in-the-blanks exercises. In relation with such phenomenon, Borg (1999) stated that grammar teaching constitutes a vague domain full of debates as to whether grammar should be taught explicitly or through learners' process of discovery or implicitly. Even Ellis (1994) stated that firm guidelines for grammar teaching seemed to be difficult to establish, a statement that may reflect phenomenon which probably still happens even now. 
In support of revitalising explicit grammar teaching, Haussamen, Benjamin, Kolln, and Wheeler (2003) asserted that because explicit grammar teaching is often considered inefficient, grammar is often ignored, merged in the teaching of speaking, reading, and writing and as a result teachers and learners seem to lose sight of the relationship between studying grammar and learning to read and write.

Fearn and Farnan (2007) agreed that grammar teaching is important, but it should be done in the framework of functional grammar as grammar teaching focusing on identification, description and definition (IDD) has failed to enhance writing performance. Fearn and Farnan (2007) continued that a functional grammar featuring what words do in sentences, rather than what words are called and how they are defined will be more effective in enhancing writing performance. Participants taught functional grammar in their study, for example, scored higher in writing performance than those taught using IDD approach of grammar teaching. They concluded that "there can be a positive interaction between grammar instruction and writing performance if the grammar is functional and used for writing purposes" (p. 1). To put it simply, it means that grammar taught and assessed as it is used in writing contexts will be more effective than that taught in isolation because in through in-context grammar teaching, learners may see the immediate connection between grammar they learn and where, when, how and in what situations they use it (Bumela, 2003).

\subsection{Concept of Complex Sentences}

Before the concept of complex sentences, the concept of sentences in general should be explained. Radford (1997) defines a sentence as "a string of word which starts with a word beginning with a capital letter and which ends with a word immediately followed by a full stop" (p. 271). This definition, however, has not touched one key grammatical aspect that should exist in any sentences, the existence of noun phrase functioning as the subject, and a verb phrase (Phillips, 2004). These subject and verb together form what is called as an independent clause (Andersen, 2014). Simply put, a sentence should contain at least one subject and one verb or one independent clause (Phillips, 2004), should begin with a capital letter and should be ended with a full stop or period (Radford, 1997).

Based on the number of the clauses and the types of the clauses, furthermore, sentences can be divided into four types. They are simple sentences, compound sentences, complex sentences, and compound-complex sentences (Andersen, 2014; Azar, 1999). Firstly, simple sentence refers to sentences which consist of a single independent clause (Haussamen et al., 2003), example of which is the sentence "You are my daughter." Secondly, compound sentences can be defined as sentences which consist of more than one independent clause (Bram, 1995). These clauses are joined using coordinating conjunctions such as and, but, or, so, and yet (Phillips, 2004). An example is the sentence "You are my daughter and I really love you." Third, complex sentences, which become the focus of the current study, are sentences consisting of an independent clause and one or more dependent clauses (Bram, 1995). In regard with this, Andersen (2014) stated that one obvious characteristic of dependent clauses is the existence of subordinating conjunctions at the beginning.

Indonesian Journal of EFL and Linguistics, Vol. 3(1), 2018 
There are many subordinating conjunctions, among which are who, which, that, because, when, while, and as. Thus, any clauses with such conjunctions at the beginning will automatically become dependent clauses. Furthermore, the last type is compound-complex sentences, which are made up of two or more independent clauses and at least one dependent clause. An example of this type of sentences is the sentence "You are my daughter, whom I care for, and I really love you."

Finally, specific about complex sentences, which consist of at least one independent clause and one or more dependent clauses, as previously mentioned, they can be divided into three categories based on the types of the dependent clauses (Phillips, 2004). These dependent clauses are noun clauses, adjective clauses and adverb clauses. First, noun clauses are dependent clauses which replace noun phrases (Phillips, 2004; Werner \& Nelson, 2007). An example of this clause can be observed in this sentence "My mom said that she really loved me." In this sentence, "that she really loved me" functions as the noun clause replacing some possible noun phrases such as it, this, or that. Second, adjective clauses are dependent clauses modifying, describing, identifying, or giving further information or elaboration about noun phrases (Phillips, 2004; Werner \& Nelson, 2007). To put it simply, adjective clauses have the function of adjectives. An example of sentences containing an adjective clause is "My mom, who is my most beloved person in the world, really loves me." In this sentence, "who is my most beloved person in the world" describes the noun phrase "my mom." Moreover, adverb clauses are dependent clauses used as adverbs (Azar, 1999; Phillips, 2004). As an adverb, an adverb clause can be placed in any positions an adverb can, and it basically tells more about a verb. In the sentence "I love you because you are my daughter," for instance, "because you are my daughter" functions as the adverb clause of the sentence explaining the reason of an action "love" stated in the independent clause.

Furthermore, apart from the aforementioned types of dependent clauses, it is also possible for complex sentences to have multiple-clause structures in the dependent clauses (Quirk \& Greenbaum, 1985). It allows each dependent clause to be superordinate to one or more other clauses. The sentence "My mom said that she always loved me even though I was very naughty when I was a child," for instance, has a multiple-clause structure in which "when I was a child" was subordinate to the clause "even though I was very naughty...," which in turn is subordinate to the clause "My mom said..." As can be seen in the example above, this structure will result in a hierarchy of clauses one within another, which often leads to sentences of great complexity.

\subsection{Complex Sentences in Writing}

Studies of complex sentences in writing have been conducted both in first language or mother tongue (L1) contexts and L2 contexts. In L1 contexts, the studies mainly focused on children's language development in writing (e.g.: Diessel, 2004; Kelly \& Safford, 2009; Wyse, 2001). Different from studies of complex sentences in L1 contexts, studies in L2 contexts focus on adults' learners. Such studies usually tried to investigate the level of university students' mastery of complex sentences in each of the four types of complex sentences mentioned above (e.g.: Subekti, 2017), and 
the relationship between the number of complex sentences and writing scores (e.g.: Cahyono et al., 2016).

Highlighting the importance of complex sentences in written communication, Krashen and Terrell (1983) stated that learners' ability to produce complex sentences in their writing shows maturity in writing. Supporting this view, Kelly and Safford (2009) asserted that "complex sentences are a marker of mature and thoughtful writing" (p. 118). This is attributed to the role of complex sentences in enabling learners to build meaning and effect in a way which is both aesthetically attractive and succinctly exact through the placing of words in independent and dependent clauses (Bram, 1995; Palmer, 1993). The use of adjective clauses within a sentence, for example, can help avoid repetitions as it enables the substitution of a pronoun for a noun phrase already mentioned before. Hence, the coherence of the composition can be enhanced.

\section{RESEARCH METHODOLOGY}

\subsection{Research Design}

The design of the current research was the "combination" of what Cahyono et al. (2016) and Subekti (2017) had conducted in their respective studies of complex sentences with some "improvements" in order to investigate this field even further to answer some aspects in the field that had not been covered or answered in the aforementioned two studies. First, different from Cahyono et al.'s (2016) study which investigated the correlation between learners' writing scores and the number of complex sentences regardless of whether these sentences were grammatical or ungrammatical, this study tried to investigate to what extent learners' mastery of complex sentences, seen from the percentage of the grammatically correct sentences, could predict their L2 writing proficiency, as seen in their writing scores. As such, the extent of the role of learners' capability of writing grammatically correct complex sentences in contributing to L2 writing proficiency can be obtained. Secondly, the same as Subekti's (2017) study, this study used the document analysis. The use of document analysis was based on a sound consideration. As Ary, Jacobs, and Razavieh, (2002) asserted, document analysis enables researchers to analyse and interpret materials within their own contexts. Hence, this allows researchers to obtain data which are considered natural and authentic (Ary et al., 2002). The participants of this study wrote their essays as assigned in their Writing class and there was no interventions whatsoever given to the participants in relation with the focus of this study. Hence, it could be stated that the participants' essays, which were analysed, were authentic.

\subsection{The Participants, Context and Ethical Consideration}

The participants of this study were ten (10) undergraduate students of English Education Department taking Essay Writing course at a university in a big city in Indonesia. At the time of the data gathering, in the first semester of 2017-2018 academic year, these students were in their third semester. Selecting English Education Department's students were based on the idea that as future teachers, they would need good command in language they would be teaching. It should be 
acknowledged, however, that the selection of the participants was partly based on convenient purpose related to the more extensive availability of data on students' English compositions in English Department's courses compared to that in nonEnglish major departments.

Furthermore, the participants' participation was obtained through the signed consent forms which I distributed on Monday, 6 November 2017. They were also explained about the nature of the research, the needed data, which were their essays and grades, and most importantly about their rights as participants. As such, these participants' voluntary participation was maintained and guaranteed (Israel \& Hay, 2006; Oliver, 2003). Upon obtaining the participants' consent and thus their voluntary participations, I analysed totally forty essays in which each of the participants contributed four of their essays. These essays were learners' Selected Essay 1, Selected Essay 2, Progress Assessment, and Final Assessment, each of which had separate grades which contributed to their final grades of the Essay Writing course.

The context of the study, more specifically, was Essay Writing class, a mandatory course offered in the third semester of the participants' department. As seen in the course syllabus, in this class, learners were required to write essays of various genres such as descriptive, expository, recount, and argumentative. The essays they were required to write should consist of five paragraphs and should at least be 25 sentences in length. The components of scoring consisted of Contents, Organisation, and Language Use, each of which had an equal weight, one third of the whole score. In this respect, mastery of grammar was directly associated with the aspect of Language Use even though some experts believe that grammar also contributes to other aspects of marking, and thus contributes to overall writing quality (Bram, 1995; Palmer, 1993).

\subsection{Data analysis}

After obtaining forty essays that the participants wrote as their assignments in Essay Writing course, I analysed each of the essays in terms of the total number of written sentences regardless of types and grammaticality, the total number of complex sentences, as well as the total number of grammatically correct complex sentences. These data were recorded at the end of each essays.

After all essays were analysed, the results of the analysis were recorded in SPSS 16 for further statistical analysis. The corresponding essays' grades for each essays were also recorded. Before conducting further analysis, I ensured that all data recorded were accurate. Descriptive analysis was then conducted to find the extent to which learners used complex sentences in their essays as well as their mastery of complex sentences. After that, correlation formulas were conducted to find respectively the relationship between learners' number of complex sentences learners wrote and L2 writing proficiency and their level of mastery of complex sentences and their L2 writing proficiency as measured with their grades for each essays. Finally, a regression analysis was conducted to find the extent to which their level of mastery could predict their L2 writing proficiency.

Indonesian Journal of EFL and Linguistics, Vol. 3(1), 2018 


\section{FINDINGS AND DISCUSSIONS}

The descriptive results of learners' scores in all four essay assignments could be observed in Table 1. As seen from the table, the minimum score students obtained was 60 while the maximum was 98.33. The mean of their writing scores was 80.22. Hence, it could be stated that in general their writing proficiency, based on the scoring criteria of Contents, Organisation, and Language Use as previously mentioned, was quite good. In terms of the length of the sentences, in average, they wrote 35.13 sentences in each of the essays, with the minimum 22 sentences, the maximum 122 sentences, and standard deviation only 15.7. The fact that mostly learners' essays length was not very different from one another might be attributed to the requirement of the writing assignment that necessitated learners to write fiveparagraph essays of at least 25 sentences in total even though their Recount essays were notably longer than those of the other types, descriptive, expository, and argumentative ones.

Table 1: Learners' Scores and Length of Essays

\begin{tabular}{|l|c|r|r|r|r|}
\hline & $\mathrm{N}$ & Minimum & Maximum & Mean & \multicolumn{1}{c|}{ Std. Deviation } \\
\hline Scores & 40 & 60.00 & 98.33 & 80.22 & 11.38 \\
\hline Total Sentences & 40 & 22 & 122 & 35.13 & 15.70 \\
\hline
\end{tabular}

From descriptive analysis on SPSS 16 as seen in Table 2, furthermore, there were some important points obtained in regard with learners' extent of using complex sentences in their essays. First, this study found that minimum use of complex sentences in learners' essay was $20 \%$. It means that in that specific essay, $20 \%$ of the sentences were in the form of complex sentences. The maximum percentage of the usage was $88.46 \%$. It means that nearly $90 \%$ of the essay was written in complex sentences. The mean percentage of the usage was $49.56 \%$, which implied that in average almost half of each of learners' essay was written in complex sentences. This number was almost identical to the number obtained in Subekti's (2017) study on complex sentences among sixth semester students of English Education Department in which $48.5 \%$ of all sentences the participants wrote in their essays were complex sentences. This result was also similar to what Cahyono et al. (2016) found in their study in which complex sentences also became the most frequently written type of sentences compared to the other types of sentences in which they found $56 \%$ of their participants' sentences were in the form of complex sentences.

Table 2: Learners' Use of Complex Sentences in Essays

\begin{tabular}{|l|r|r|r|r|r|}
\hline & $\mathrm{N}$ & Minimum & Maximum & Mean & \multicolumn{1}{c|}{$\begin{array}{c}\text { Std. } \\
\text { Deviation }\end{array}$} \\
\hline Complex Sentences & 40 & 5 & 33 & 16.75 & 5.90 \\
\hline $\begin{array}{l}\text { Number of Complex Sentences } \\
\text { (in percentage) }\end{array}$ & 40 & 20.00 & 88.46 & 49.56 & 16.17 \\
\hline
\end{tabular}


Interestingly, this result contradicted to Qonitatun's (2016) study in Kalimantan, Indonesia. The study found that simple sentences, rather than complex sentences, were the most frequently written of all in all of five fourth semester student participants' essays. The contradicting result of the present study and that of Qonitatun's (2016) might be attributed to the interplay of some reasons. The first was the possibility of the different level of proficiency between the participants in the present study and that of Qonitatun (2016). Secondly, the student participants' preference in writing could also have some contributions in which some students might like to write longer utterances, some others might prefer writing shorter ones. Finally, the nature of the writing assessment of the two studies might be different as well. The present study, Cahyono et al.'s (2016), and Subekti's (2017) studies, all of which produced the same result on complex sentences being the most frequently written type of all, for examples, used upper writing courses in their respective English Education Departments' curricula, which necessitated learners to write relatively long essays. Qonitatun (2016), unfortunately, did not provide detailed requirements of the writing assessment used in her study and she did not give further explanations on this specific result of her study either.

Despite the different result of the present study with that of Qonitatun (2016) above, the result which were similar to at least two previous studies (e.g.: Cahyono et al., 2016; Subekti, 2017), may further suggest learners' acknowledgement of the importance of complex sentences in writing. That is to state that writing necessitated them to communicate such complex ideas and complex sentences had been their primary choice to attain that goal. This may be attributed to the capability of complex sentences in building both meaning and effect in a succinctly exact and appealing way through the use of subordinations (Palmer, 1993).

\subsection{Research Question 1: How is the relationship between learners' number of complex sentences and their $\mathrm{L} 2$ writing proficiency?}

As seen from seen in Table 3, the study found that learners' number of complex sentences did not have a statistically significant relationship with their writing scores with the strength of the correlation being very weak, $r(40)=-.08, p>.05$. In other words, it was safe to state that these two variables did not correlate one another. This specific result was very different from that of Cahyono et al. (2016) in which they found that their participants' quantity of written complex sentences positively correlated with their writing scores. This result was rather surprising in the way that the use of complex sentences in writing had very small, insignificant relationship with the quality of writing as measured with grades. At first glance, this result was contrary to some experts' idea on the power of complex sentences in improving writing quality (e.g.: Bram, 1995; Palmer, 1993)

If analysed further, however, this result may not be as surprising in the way that the number of complex sentences learners wrote may not always positively correspond to their mastery. That is to say that those who wrote more complex sentences might make so many grammatical mistakes in those sentences to the point of those ungrammatical complex sentences, instead of improving writing quality, ruining the flow of idea and leading to confusing contents, thus poor quality of writing. Simply

Indonesian Journal of EFL and Linguistics, Vol. 3(1), 2018 
put, experts' idea on the role of complex sentences in improving writing quality should be seen in the framework of grammatical complex sentences. That was not to say that the result of Cahyono et al.'s (2016) study on the positive correlation between the quantity of complex sentences and writing scores was not legitimate. It was to state that correlating quantity of complex sentences regardless of grammaticality with writing scores may be misleading if not interpreted with cautions. In Cahyono et al.'s (2016) study, for instance, it was possible that most of the participants' complex sentences which were analysed were grammatical and thus positively correlated with their writing scores. In this study, for example, it was possible that despite the large quantity of complex sentences written, they contained more grammatical errors, the thus it produced a completely different result from that of Cahyono et al.'s (2016) study.

Table 3: Correlation between Learners' Number of Complex Sentences and L2 Writing Proficiency

\begin{tabular}{|ll|c|}
\hline & & Number of Complex Sentences \\
\hline \multirow{4}{*}{ Writing Scores } & Pearson Correlation & $-.083^{*}$ \\
& Sig. (2-tailed) & .612 \\
& $\mathrm{~N}$ & 40 \\
\hline
\end{tabular}

*. Correlation is significant at the 0.05 level (2-tailed).

\subsection{Research Question 2: How is the English Education Department's students' mastery of complex sentences?}

Through analysing the percentage of grammatically correct complex sentences in each of the forty essays, and performing descriptive analysis, this study obtained some important results with regard to learners' mastery of complex sentences. First, the lowest mastery was found in the level of $11.11 \%$. It means that in that essay, $88.89 \%$, almost all of the complex sentences the participant wrote, was ungrammatical. On the other hand, $93.75 \%$ became the maximum percentage of grammatically correct complex sentences written in an essay. It means that nearly all of the complex sentences written in that essay were grammatically accurate. The mean percentage was 57.58, which indicated that in general more than $40 \%$ of all written complex sentences in learners' forty essays was grammatically incorrect. Even though not specifically investigating complex sentences, Lirola and Irwin (2016) already hinted in their study of English writing in Spanish context that ungrammaticalities in L2 writing was to be expected. Thus, the present study's result indicating that there were ungrammaticalities in learners' essays was not at all surprising. However, that he standard deviation being 23.69 may indicate that the gap between those with high percentage of grammaticality and those with low percentage was a bit large. This may suggest that there was a large discrepancy of mastery of complex sentences among learners. Table 4 below summarised the results. 
Table 4: Learners' Mastery of Complex Sentences

\begin{tabular}{|l|r|r|r|r|r|}
\hline & $\mathrm{N}$ & Minimum & Maximum & Mean & Std. Deviation \\
\hline $\begin{array}{l}\text { Correct Complex Sentences } \\
\text { (in percentage) }\end{array}$ & 40 & 11.11 & 93.75 & 57.58 & 23.69 \\
\hline
\end{tabular}

\subsection{Research Question 3: To what extent does their mastery of complex sentences predict their $\mathbf{L} 2$ writing proficiency?}

Before the finding on the extent learners' mastery of complex sentences could predict their L2 writing proficiency, it may be worthwhile to see the relationship between the two variables. As seen in Table 5, this study found that there was statistically significant positive correlation between learners' mastery of complex sentences, as seen from the percentage of grammatical complex sentences, and their L2 writing proficiency, as seen from their writing scores or grades. The strength of the correlation was in moderate level, $r(40)=.44, p<.01$. It means that essays with more grammatical complex sentences tended to obtain higher scores than those with less grammatical complex sentences. This result strengthened the idea of the importance of grammar mastery, especially mastery of complex sentences, in improving writing quality (Kelly \& Safford, 2009; Krashen \& Terrell, 1983).

Table 5: Correlation between Learners' Mastery of Complex Sentences and L2 Writing Proficiency

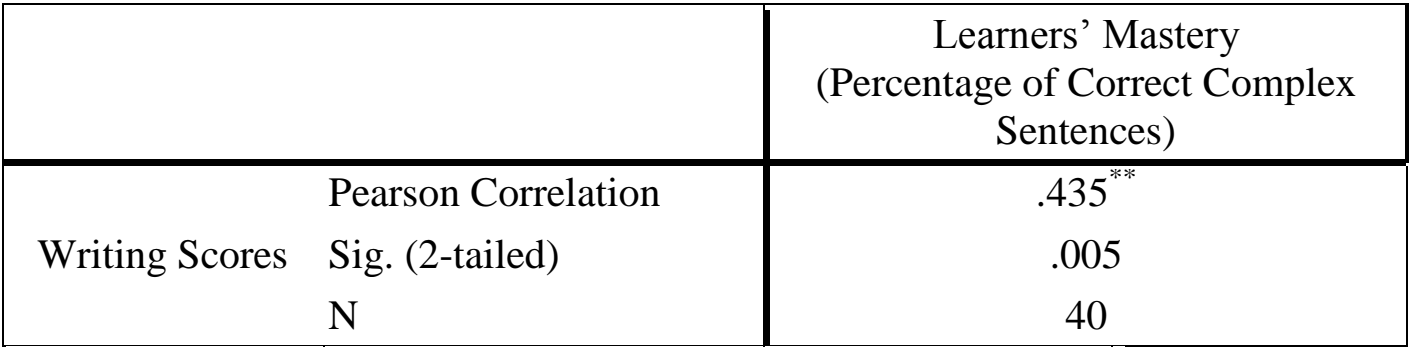

**. Correlation is significant at the 0.01 level (2-tailed).

Furthermore, to find out to what extent learners' mastery of complex sentences could actually predict their L2 writing proficiency, a regression analysis was conducted. Table 6 below summarised the results.

Table 6: Regression Results with Writing Scores as the Dependent Variable

\begin{tabular}{|r|l|r|r|r|}
\hline Model & $\mathrm{R}$ & R Square & Adjusted R Square & Std. Error of the Estimate \\
\hline 1 & $.435^{\mathrm{a}}$ & .19 & .17 & 10.38 \\
\hline
\end{tabular}

a. Predictors: (Constant), learners' mastery of complex sentences

From the above table, it could be stated that learners' mastery of complex sentences could predict $19 \%$ of variance of learners' L2 writing proficiency as seen from their writing scores. This result indicated that mastery of complex sentences was an 
important predictor of L2 writing proficiency. Hence, learners' mastery of complex sentences was an important aspect of grammar that needs to obtain more attention in L2 learning.

\section{CONCLUSION}

In the light of this study's results, there are some pedagogical implications that need to be emphasised. First, as complex sentences were found to be the most frequently written type of sentences compared to the others, it is suggested that exposure on the use of complex sentences in writing context should be promoted in English Education Department's curriculum. The practices may include the use of writing assessment in Grammar classes with the reduction of isolated Grammar exercises like cloze exercises and fill-in-the blank exercises. That is to acknowledge that mastery of grammar means mastery of its use in contexts (Bumela, 2003; Fearn \& Farnan, 2007). Furthermore, that this study found an insignificant negative relationship between the number of complex sentences and writing scores while it found a significant moderate relationship between learners' mastery of complex sentences and writing scores may indicate that in order to improve writing quality, it is really important to write grammatically correct complex sentences rather than a large number of complex sentences regardless of grammaticality. These strikingly different results of the two correlation analyses may also give some kind of support that grammatically inaccurate complex sentences, instead of helping improve overall writing quality, may even reduce it. Moreover, that this study found learners' mastery of complex sentences became an important predictor of their L2 writing proficiency strengthens the needs for English Education Department teachers, especially those of Grammar classes, to help learners to improve their mastery of complex sentences through writing assessments.

Furthermore, the limitations of this study should also be acknowledged to determine the extent of its relevance as well as its possible weaknesses. First, this study used theories of syntax as the framework to determine the participants' mastery. Thus, this study's results should be viewed from this framework as well. In addition, the tabulation of learners' mastery was based on manual assessment on grammatical correctness. Thus, despite the optimal effort, grammar fatigue in which assessors missed ungrammaticalities due to fatigue during assessment process, which was also experienced by the markers or assessors in Lirola's and Irwin's (2016) study, may also happen in this study. Furthermore, that this study found complex sentences were the most frequently written type of sentences in learners' essays could be generalised to a wider population, at least in Indonesian university contexts. At least, two previous studies also produced the same results (see Cahyono et al., 2016; Subekti, 2017), despite that there was one study produced a different result, Qonitatun's (2016) study, and thus, could be overlooked as it only involved five participants with little details on the nature of its essay writing assessment under study. What is more, as there were conflicting results between this study and the study conducted by Cahyono et al. (2016) on the relationship between the number of complex sentences and writing scores, further research needs to be conducted. Many other variables may be at play, for examples, participants' preferences in writing,

Indonesian Journal of EFL and Linguistics, Vol. 3(1), 2018 
their writing styles, as well as their general command of language. Thus, the variables included in future studies should be more specified to avoid any simplistic analysis and conclusion which may be misleading.

In the light of the implications and limitations of the study, some suggestions on future studies could be stated. The first is to investigate learners' most frequent aspect of ungrammaticalities. That is intended to know in which parts learners need improvements the most and thus to enable teachers to help them achieve that goal (Sihombing, Nissa, \& Estrelita, 2015). Secondly, it is suggested to conduct studies on the relationship between other aspects of grammar mastery and L2 writing proficiency.

\section{REFERENCES}

Andersen, S. (2014). Sentence Types and Functions. Retrieved February 23, 2018, from http://www.sjsu.edu/writingcenter/handouts/Sentence Types and Functions.pdf

Ariyanti, A. (2016). The Teaching of EFL Writing in Indonesia. Dinamika Ilmu, 16(2), 263-277.

Ary, D., Jacobs, L., \& Razavieh, A. (2002). Introduction to Research in Education (Sixth Edition). Belmonth, CA: Wadsworth/Thomson: Wadsworth/Thomson Learning.

Azar, B. (1999). Understanding and Using English Grammar. New York: Pearson Education.

Borg, S. (1999). Teachers' theories in grammar teaching. ELT Journal, 53(3), 157167.

Bram, B. (1995). Write Well: Improving Writing Skill. Yogyakarta: Kanisius.

Bumela, L. (2003). Responding and Analysing: Stages of Teaching Functional Grammar in Indonesian context. Indonesian Journal of Applied Linguistics, 4(1), 70-86.

Cahyono, B. Y., Mukminatien, N., \& Amrina, R. (2016). Indonesian Students ' Writing Proficiency and Their Ability in Using Complex Sentences. International Journal of Studies in English Language and Literature (IJSELL), 4(9), 22-32. https://doi.org/http://dx.doi.org/10.20431/2347-3134.0409004

Diessel, H. (2004). The Acquisition of Complex Sentence. Cambridge: Cambridge University Press.

Ellis, R. (1994). The Study of Second Language Acquisition. Oxford: Oxford University Press.

Fearn, L., \& Farnan, N. (2007). When Is a Verb ? Using Functional Grammar to Teach Writing. Journal of Basic Writing, 26(1), 63-87.

Hartfield, V. F., Jacobs, H. L., Zinkgraft, S. A., Wormuth, D. R., \& Hughey, J. B. (1985). Learning ESL Composition. Rowley, MA: Newbury House.

Haussamen, B., Benjamin, A., Kolln, M., \& Wheeler, R. S. (2003). Grammar Alive! A Guide for Teachers. Urbana, Illinois: National Council of Teachers of English (NCTE).

Israel, M., Hay, I. (2006). Research Ethics for Social Scientists. London: Sage

Indonesian Journal of EFL and Linguistics, Vol. 3(1), 2018 
Publications.

Kelly, A., \& Safford, K. (2009). Does teaching complex sentences have to be complicated? Lessons from children' s online writing. Literacy UKLA, 43(3), 118-122.

Krashen, S., Terrell, T. (1983). (1983). The Natural Approach: Language Acquisition in the Classroom. Oxford: Oxford University Press.

Lirola, M. M., \& Irwin, D. S. (2016). Challenges in the Application of Genre Theory to Improve L2 Academic Writing: Effective Reports and Assessment. ASIAN TEFL, $\quad 1(1), \quad 39-54 . \quad$ https://doi.org/doi: http://dx.doi.org/10.21462/asiantefl.v1i1.4

Oliver, P. (2003). The Student's Guide to Research Ethics. New York: Open University Press.

Oshima, A., Hogue, A. (2006). Writing Academic English. White Plains, NY: Pearson.

Palmer, R. (1993). Write in Style: A Guide to Good English. London: E \& FN SPON.

Phillips, D. (2004). Longman: Introductory Course for the TOEFL Test. New York: Pearson Education, Inc.

Qonitatun, Q. (2016). The Quality of Essay Writing of Indonesian EFL Learners. ASIAN TEFL, $1(1), \quad 55-76 . \quad$ https://doi.org/doi: http://dx.doi.org/10.21462/asiantefl.v1i1.6

Quirk, R., Greenbaum, S. (1985). A University Grammar of English. Harlow, Essex: Longman Group Limited.

Radford, A. (1990). Transformational Grammar. Cambridge: Cambridge University Press.

Radford, A. (1997). Syntax: A Minimalist Introduction. Cambridge: Cambridge University Press.

Sihombing, R., Nissa, A. K., Estrelita, A. (2015). Students' Written Production Error Analysis in the EFL Classroom Teaching: A Study of Adult English Learners Errors. LLT Journal, 18(2), 125-132.

Subekti, A. S. (2017). A Study of the Mastery of Complex Sentences of Pre-Service English Teachers. Ahmad Dahlan Journal of English Studies (ADJES), 4(2), $1-12$.

Werner, P. K., Nelson, J. P. (2007). Mosaic 2 Grammar (Silver). Singapore: McGraw-Hil.

Wyse, D. (2001). Grammar. For Writing? A Critical Review of Empirical Evidence. British Journal of Education Studies, 49(4), 411-427. 